\title{
Accident at river-crossing underwater oil pipeline
}

\author{
Tamila Titova ${ }^{1}$, Rasul Akhtyamov ${ }^{1}$,Elina Nasyrova $^{2, *}$ and Alexey Elizaryev ${ }^{2}$ \\ ${ }^{1}$ Emperor Alexander I St. Petersburg State Transport University, St. Petersburg, Russia \\ ${ }^{2}$ Ufa State Aviation Technical University, Ufa, Russia
}

\begin{abstract}
The aim of this article is to present an approach enabling to define the flame spread velocity at spill fire on the river, taking into account the wind speed. Due to constant oil supply from the pipeline during the leakage, an oil slick will increase until its borders reach river banks. Formulas for determining the main parameters of oil spill on the river in case of an accident at underwater oil pipeline were suggested. The formulas include the initial data determined in the field, for instance, flow and wind speed, as well as water temperature. An example of the change of oil slick parameters on the river was demonstrated. The spread rate of spilled oil and the flame spread speed were calculated. It was shown that on narrow rivers, an oil slick takes the form of a river bed within a few minutes and moves in the direction of the flow. Determination of oil spill parameters given in the study is sufficient for accident response implementation: - spread rate of spilled oil allows for distance calculation in order to install oil booms; - flame spread speed in conjunction with the oil slick size will make it possible to calculate the fire extinguishing means. The obtained results, undoubtedly, require testing in experimental conditions, which is the purpose of further research.
\end{abstract}

\section{Introduction}

Oil pipes are widely used all over the world for petroleum pumping. Sometimes different barriers arise during the construction of oil pipelines, such as roads, railway crossings and water objects. Crossing of rivers by oil pipelines is solved by means of underwater pipes construction. It should be noted that pipelines passing through streams with width less than $15 \mathrm{~m}$ and depth less than $1.5 \mathrm{~m}$ do not belong to underwater pipelines [1].

In the process of oil pipelines operation under the influence of various factors, accidents occur annually, accompanied by uncontrolled oil leakage [1, 2]. The reasons of leakage described by Zhang et al. [3] and Mohamed et al. [4]: mechanical damage of oil pipelines, corrosion (external and internal), pipe defect, welding defects, human mistakes in the pipeline operation or maintenance. Ilman and Kusmono [5] assumed that oil leakages of corroded underwater pipeline occur after 27 years in service. Some authors also identify

\footnotetext{
* Corresponding author: ElinaSagitovna@yandex.ru
} 
natural causes of underwater oil pipelines destruction, for example, riverbed deformation or natural disasters, such as earthquakes [4] and floods [6].

Different technologies are designed for detection and location of pipeline leakage and damage (sensor networks [4]) as well as modelling of leakage process (software ANSYS FLUENT® 15.0 [7]).

An oil spill occurs in depressurization of underwater oil pipelines, which leads to $[7,8]$ :

- river pollution and water supply failure of nearby village;

- spill fire, followed by environmental pollution with combustion products, damage to building structures on its way. Also combustion products create extreme conditions during oil spill liquidation measures. The resulting smoke poses a risk to rescuers' safety [9].

Mullina and Champ [10] described a case of using the spill fire as a purposeful method for its liquidation (in situ burning).

There exist a number of modern models for oil spill trajectory simulation [11]: GNOME (General NOAA Operational Modeling Environment), ADIOS (Automated Data Inquiry for Oil Spills), Trajectory Analysis Planner (TAP) designed for sea spills. However, the Samuels et al. [12]; Danchuk and Willson [13] used these models in their works to determine the oil spill trajectory on the river. Also, semiempirical formulas introduced by J. Fay [14] describe the change in oil slick parameters at the spread phase under the action of surface tension forces. However, they are not applicable for rivers and elliptical shape of oil slick.

Some works devoted to the study of other hydrocarbon substances. Zhao et al. [15] analyzed heptane discharge. The results show that if there is no ignition, the spread rate is approximately linear to the discharge rate and the burning rate of spill fires on water surface is approximately 0.57 times smaller than that of pool fires for large-scale burning.

Understanding of the oil spill fire characteristics is the primary condition for analyzing fire direction and taking operational measures for its liquidation. Sometimes the experimentally obtained relations for oil spill fire characteristics are not comparable with the real, as Zhen et al. [16] show in their work: the point source model has a large error for pool fires with the diameter greater than $10 \mathrm{~m}$.

The process of oil slicks burning on the river is limited by flow rate, meteorological parameters and oil characteristics $[17,18]$. The river flow rate and wind direction have the greatest impact on fire velocity. For instance, in case of headwind with speed of $1.25 \mathrm{~m} / \mathrm{s}$, the fire practically does not spread over an oil spill, which moves along the river with flow rate of $0.8 \mathrm{~m} / \mathrm{s}$.

As a result, the existing methods are estimating parameters of oil spills mainly at sea [19-22]. In this connection the aim of this article is to present a comprehensive approach making it possible to define the flame spread velocity at spill fire on the river, taking into account the wind speed. The obtained formulas will allow for quick assessment of the oil spill fire parameters.

\section{Methods}

In an emergency, it is suggested to evaluate the oil spill fire parameters in the following sequence.

1. The point of oil ascent (fig. 1). 


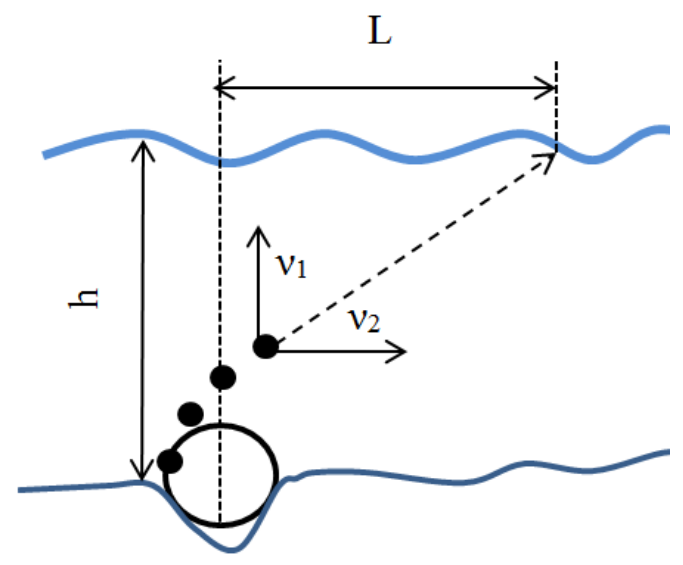

Fig. 1. The scheme of oil particles ascent, where: $h$ - river depth, $m ; v 1$ - ascent rate of oil particles, $\mathrm{m} / \mathrm{s} ; \nu 2$ - flow rate, $\mathrm{m} / \mathrm{s} ; \mathrm{L}$ - distance from the oil pipeline to point of oil ascent, $\mathrm{m}$.

Distance from the oil pipeline to the point of oil ascent, $\mathrm{m}$ :

$$
L=\frac{h \cdot v_{2}}{v_{1}}
$$

Ascent rate of oil particles is usually determined by the Stokes equation [23], taking into account the following:

- acceleration of gravity $9.81 \mathrm{~m} / \mathrm{s} 2$;

- diameter of oil particles 2 10-3 m;

- water density $103 \mathrm{~kg} / \mathrm{m} 3$;

- dynamic viscosity of water is the function of density and kinematic viscosity, estimated by Poiseuille's equation. Thus, the following dependency is obtained:

$$
v_{1}=0.00122 \cdot\left(10^{3}-\rho_{\text {oil }}\right) \cdot\left(1+0.0337 \cdot t_{w}+0.000221 \cdot t^{2}{ }_{w}\right)
$$

where $\rho_{\text {oil }}$ - oil density, $\mathrm{kg} / \mathrm{m} 3$;

$t_{w}$ - water temperature, ${ }^{\circ} \mathrm{C}$.

2. The spread rate of spilled oil.

If vectors of the river flow and wind coincide, the spread rate of spilled oil in the wind $\operatorname{direction}\left({ }^{v_{3}^{\prime}}, \mathrm{m} / \mathrm{s}\right)$ will be:

$$
v_{3}^{\prime}=v_{2}+0,05 \cdot v_{4}
$$

where $v_{2}$ - river flow rate, $\mathrm{m} / \mathrm{s}$;

$v_{4}$ - wind speed, $\mathrm{m} / \mathrm{s}$.

The spread rate of spilled oil is perpendicular to the wind direction $\left({ }^{\prime \prime}, \mathrm{m} / \mathrm{s}\right)$ according to the experimental data [17] - about $30 \%$ from $v_{3}^{\prime}$. Otherwise, the spread rate of spilled oil is equal to the flow rate.

In the absence of wind speed data, Gumbel double exponential distribution is used: 


$$
v_{4}(t)=\bar{v}_{4}+\frac{\sigma_{v 4}}{\sigma_{y}}(\ln t-\bar{y})
$$

where $\bar{\nu}_{4}$ - the average of wind speed;

$\sigma_{v_{4}}$ - standard deviation of wind speed;

$\bar{y}, \sigma_{y}$ - dimensionless values, depending on sample data, estimated by Gumbel tables.

3. The slick length.

By means of J. Fay [14], formula designed to estimate the maximum possible area of oil slick, the maximum length of $\operatorname{slick}\left({ }{ }_{\max }, \mathrm{m}\right)$ is calculated:

$$
l_{\max }=\frac{10^{5} \cdot V^{3 / 4}}{z}
$$

where $V^{3 / 4}$ - volume of spilled oil, m3;

$z$ - river width, $\mathrm{m}$.

4. The flame spread speed.

If the spill fire is taken as surface fire spread model, the flame will move in wind direction at speed $v_{5}, \mathrm{~m} / \mathrm{s}$ :

$$
v_{5}=1.65 \cdot C \cdot v_{4}^{n}
$$

where $\mathrm{n}$ and $\mathrm{C}$ - coefficients depending on fire duration (table 1).

Table 1. Coefficients $\mathrm{n}$ and $\mathrm{C}$.

\begin{tabular}{|l|l|l|l|l|}
\hline $\mathbf{t}$, minutes & $\mathrm{t}<10$ & $10<\mathrm{t}<20$ & $20<\mathrm{t}<60$ & $\mathrm{t}>60$ \\
\hline $\boldsymbol{n}$ & 0.70 & 0.73 & 0.76 & 0.84 \\
\hline $\boldsymbol{C}$ & 0.55 & 0.72 & 0.84 & 0.87 \\
\hline
\end{tabular}

Oil spill fire parameters were calculated in the given study in accordance with the proposed method and with the following initial conditions:

- the oil spill ( $\rho_{\text {oil }}=860 \mathrm{~kg} / \mathrm{m} 3$ ) was considered as a result of underwater pipeline depressurization (depth under water $\mathrm{h}=6 \mathrm{~m}$ ). The reason for pipeline depressurization was the vibration of the blurred area of the underwater pipeline due to the influence of water stream;

- guillotine destruction of underwater pipeline with leakage mass of 130 tons.

- river characteristics: flow rate $v_{2}=2.2 \mathrm{~m} / \mathrm{s}$; river width $z=50 \mathrm{~m}$; water temperature

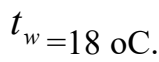

- meteorological conditions: wind speed $v_{4}=2.3 \mathrm{~m} / \mathrm{c}$. Vectors of the river flow and wind coincide.

- the oil spill ignites in 30 minutes after oil pipeline depressurization;

- the distance to the nearby city water intake point is $20 \mathrm{~km}$.

\section{Results and Discussion}

The following conclusions were obtained: 
- the impact of coastal waves is excluded due to the small size of the river compared to sea;

- the uniform oil is spread over water surface;

- oil is burning constantly, layer-by-layer, during spill fire.

It is assumed in the given study, that at first, in case of oil spill on the river, an oil slick in the form of an ellipse is formed. Due to the constant oil supply from pipeline during the leakage, the oil slick will increase until its borders reach river banks. There will be a permanent deformation of oil slick shape. When the oil slick reaches the river banks, it will take the form of the river bed. In this regard, the slick area is calculated as a rectangle area.

The presence of shallow areas covered with vegetation creates favorable conditions for oil accumulation. When the oil slick reaches the river banks, a reformation occurs. In some cases, the oil slick is pressed by the wind to the river bank and takes the form of a wedge: the coastal layer of oil has the largest thickness, whereas, on the windward side - the smallest. In other cases, when the effect of the wind is insignificant, the thickness of the layer is uniform.

The oil slick will spread not only in relation to the pipeline, but also move along the river. The drift direction of oil spill is determined by adding the vectors of wind direction and river flow.

The oil slick will be constantly transformed during its movement along the river. In the ice-free period, about $25 \%$ of the oil evaporates, the remaining part emulsifies (direct emulsion: $80 \%$ water $+20 \%$ oil) due to which the oil film dissipates.

In case there is an ignition source, oil burning will occur on the water surface. The flame front will spread in wind direction. Fire throwing to the coastal zone, followed by ignition is possible.

1. In accordance with the initial data of formula 2 the ascent rate of oil particles equals $v 1=0.29 \mathrm{~m} / \mathrm{s}$.

At this speed, the oil floats to the river surface at a distance $\mathrm{L}=45.5 \mathrm{~m}$ from the pipeline.

2. Taking into account the initial data of formula 3, the spread rate of spilled oil in the

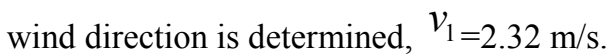

Dependence of oil slick size with the time period is shown in fig. 2.

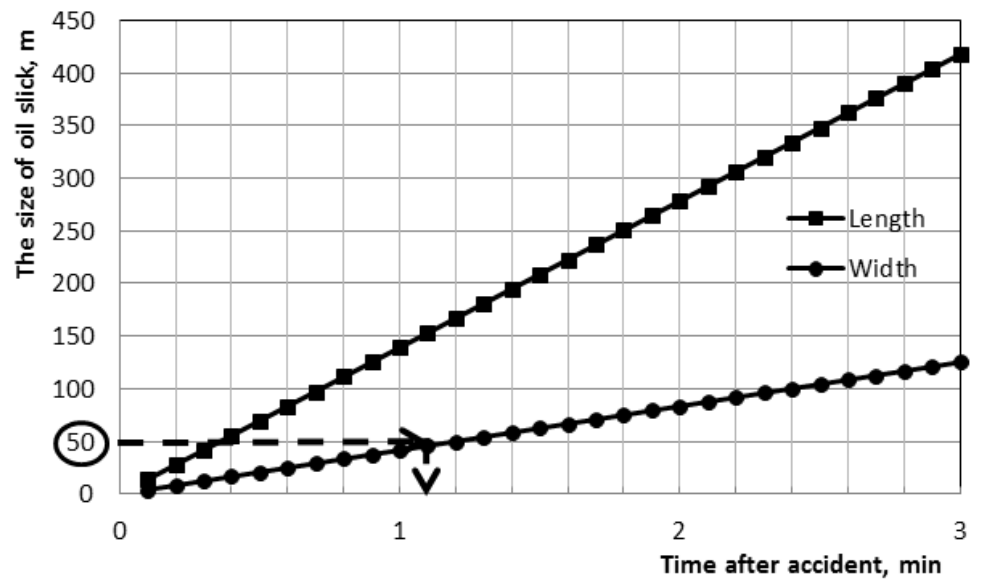

Fig. 2. Dependence of oil slick size to the time period. 
As it is shown in figure 2 , in case of the spread rate $v_{1}=2.32 \mathrm{~m} / \mathrm{s}$, the oil slick will reach the river banks in 1.1 minutes after the oil comes to the river surface. After that the oil slick will move along the entire width of the river bed.

3. Evaporated to $25 \%$ of mass (32.5 tons). The volume of remaining oil equals $\mathrm{V}=83.9106 \mathrm{~m} 3$.

The maximum possible length of slick is $1 \max =69.3 \mathrm{~km}$.

If no measures are taken to liquidate the oil spill, the slick will reach the city water

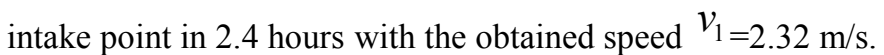

4. Taking into account the initial data of formula 6 and table 1, the flame spread speed is determined, $v_{4}=2.61 \mathrm{~m} / \mathrm{s}$.

For comparison the flame spread speed is estimated by means of the formula introduced by Anderson H.E. [24] for surface fire spread:

$$
v_{4}=1.16 \cdot \exp \left(0.0432 \cdot v_{3}\right)
$$

By Anderson H.E. $v_{4}=1.28 \mathrm{~m} / \mathrm{s}$. As it is seen, the results differ significantly.

Studies of oil spill parameters are carried out by authors in order to calculate the stock of sorbent materials and the main parameters of engineering structures for the liquidation of accidents. For instance, Melkozerov et al. [25] calculated the spread rate of spilled oil to determine the length of booms. However, the flow rate was excluded in calculations and only the wind impact was considered. Also, the paper does not consider the case of oil ignition.

\section{Conclusions}

1. The authors of the study in question have made an attempt to give theoretical explanation for flame spread speed of oil spill fire on the river. The formulas for determining the main parameters of oil spill on the river in an accident at underwater oil pipeline were introduced. The formulas can be used in practice, as they include the initial data determined in the field, for example, flow and wind speed, water temperature.

2. Using the example, we showed the change in oil slick parameters on the river was demonstrated by an example. The spread rate of spilled oil and the flame spread speed were calculated. It was shown that on narrow rivers (less than $60 \mathrm{~m}$ width), the oil slick takes the form of a river bed within a few minutes and moves in the direction of the flow. Nevertheless, there is a high probability of fire throwing to the coastal zone, followed by ignition.

3. The calculation of oil spill parameters proposed in the study was sufficient to carry out the liquidation activities:

- spread rate of spilled oil allows for distance calculation in order to install oil booms;

- the decision to close water intake points was made, taking into account the maximum possible length of the oil slick and its comparison with the distance to the nearby village;

- flame spread speed in conjunction with the oil slick size will make it possible to calculate the fire extinguishing means.

4. The assumptions given in the study were introduced due to immediacy and limited time for calculation of spill fire parameters in case of emergency. The obtained results, undoubtedly, require testing in experimental conditions, which is the purpose of further research. 


\section{Acknowledgement}

The presented research was financially supported by the Russian Science Foundation (grant no. 17-77-30006).

\section{References}

1. T.S. Titova, R.G. Akhtyamov, G.A. Bukharbaeva, Ind. Saf. 3 (2016)

2. R.K. Sharma, B.R. Gurjarab, A.V. Singhalc, S.R. Wated, S.P. Ghuged, R. Agrawale, Saf. Sci. 72 (2015)

3. C. Zhang, T.X. Qin, S. Huang, J.S. Wu, X.Y. Meng, MATEC Web of Conferences 38 (2018)

4. N. Mohamed, I. Jawhar, J. Al-Jaroodi, L. Zhang, Sensors 11 (2011)

5. M.N. Ilman, Kusmono, Case Stud. in Eng. Failure Anal. 1 (2014)

6. Z.P. Ren, C.H. Liu, F.F. Bie, Appl. Mech. Mater. 638-640 (2014)

7. C.A. Sousa, O.J. Romero, Latin Am. J. Energy Res. 1 (2017)

8. C. Sun, D. Mao, T. Zhao, X. Shang, Y. Wang, M. Duan, Aquat. Procedia 3 (2015)

9. R.G. Akhtyamov, A.N. Elizaryev, E.S. Nasyrova, Planning for rescue and other emergency operations (LAP LAMBERT, Saarbrucken, 2012)

10. J.V. Mullina, M.A. Champ, Spill Sci. Technol. Bull. 4 (2003)

11. A. Elizaryev, G. Maniakova, A. Longobardi, E. Elizareva, R. Gabdulkhakov, A. Nurutdinov, R. Khakimov, Int. J. Eng. Technol. 7 (2018)

12. W.B. Samuels, D.E. Amstutz, R. Bahadur, C. Ziemniak, Earth Sci. Res. 2 (2013)

13. S. Danchuk, C.S. Willson, Environ. Sci. Pollut. Res. 2 (2010)

14. D. Ibarra-Mojica, Á. Romero, C. Barajas-Ferreira, V. Kafarovand, C. Barajas-Solano, Int. Oil Spill Conf. Proc. 1 (2017)

15. J. Zhao, H. Huang, Y. Li, B. Su, N. Zhang, J. Loss Prevention Process Industries 43 (2016)

16. C. Zhen, W. Xiao-Na, S. Wen-Hua, L. Ling-Yue, W. Xiao-Di, Phys. Combust. Explosion 3 (2014)

17. M. Liab, S. Lua, R. Chena, J. Guoa, C. Wang, Fuel 184 (2016)

18. Y. Li, H. Huang, Z. Wang, J. Zhang, C. Jiang, R. Dobashi, J. Loss Prevention Process Industries 33 (2015)

19. T.M. Alves, E. Kokinou, G. Zodiatis, R. Lardner, C. Panagiotakis, H. Radhakrishnan, Environ. Pollut. 206 (2015)

20. H.Z. Jiahui, Y.H. Zhao Appl. Ocean Res. 64 (2017)

21. J. Lu, F. Yuan, J.D. Mikkelsen, C. Ohm, E. Stange, M. Holand, IOP Conf. Series: Earth Environ. Sci. 82 (2017)

22. J.R. Nelson, T.H. Grubesic, Prog. Phys. Geography: Earth and Environ. 1 (2018)

23. H. Zhu, P. Lin, Q. Pan, Energy 64 (2014)

24. K. Chetehouna, E.E. Tabach, L. Bouazaoui, N. Gascoin, Process Safety Environ. Protect. 98 (2015)

25. V.M. Melkozerov, S.I. Vasilev, AI.A. Velp, Syst. Methods. Technol. 9 (2011) 